\title{
Grupo Casulo: ensino/aprendizagem de arte, design, ciência da computação e eletrônica têxtil
}

\author{
Grupo Casulo: enseñanza/aprendizaje de arte, diseño, informática y \\ electrónica textil.
}

\author{
Casulo group: learning/teaching of art, design, computer science and \\ e-textile
}

\author{
Thatiane Mendes Duque \\ Universidade do Estado de Minas Gerais (UEMG) \\ ThatianeMendes@hotmail.com \\ Fabio Henrique Dias Máximo \\ Universidade Federal do Amazonas (UFAM)
}

RESUMO

Este artigo apresenta uma análise sobre experiências realizadas com eletrônica têxtil pelo grupo Casulo. Casulo é um grupo de pesquisa e desenvolvimento tecnológico interdisciplinar (arte, design, ciência da computação e eletrônica). Tem como intuito investigar vestimentas eletrônicas sensíveis ao corpo e ao ambiente. Também busca a experimentação com criação de acessórios pessoais e vestimentas "inteligentes" baseados em Arduino Lilypad e impressão 3d.

Palavras chave: Ensino, Aprendizagem, Arte, Design, Eletrônica Têxtil

\section{RESUMEN}

Este artículo presenta un análisis de experimentos realizados con electrónica textil por el grupo Casulo. Casulo es un grupo interdisciplinar de investigación y desarrollo tecnológico (arte, diseño, informática y electrónica). Su objetivo es investigar la ropa electrónica sensible al cuerpo y al medio ambiente. También busca la experimentación con la creación de accesorios personales y ropa "inteligente" basada en Arduino Lilypad e impresión 3D.

Palabras clave: Enseñanza, Aprendizaje, Arte, Diseño, Electrónica Textil

\section{ABSTRACT}

Experiments that mixed fabrics and electronic devices based on the Arduino Lilypad and 3D printing were used to investigate how wearables work and fit in our bodies. Thus, we formed a group called Casulo, with interdisciplinary students (art, design, computer science, electronics) which supported the development of wearables and tested them.

Keywords: Teaching, Learning, Art, Design, E-textile 


\section{INTRODUÇÃO}

O nome Casulo refere-se a um tipo de pele-membrana que protege, mas que também possibilita a metamorfose da forma/estrutura/subjetividade corpórea, capacitando o "antigo corpo" para novas possibilidades e afetos. O grupo tem como objetivo principal aplicar conhecimentos de arte e design, aspectos da prototipagem eletrônica como ferramenta criativa e a criação de modelos de acessórios e roupas interativas através do sensoriamento do corpo e do ambiente.

Os processos práticos são derivantes de pesquisas sobre as possibilidades conceituais dos vestíveis, uma vez que são sensíveis ao corpo do usuário, às suas emoções e seus afetos com o mundo. Em resumo, o intuito é fomentar reflexões sobre a roupa e joias tecnológicas que criam memórias e narrativas contemporâneas de afeto e intimidade sobre o corpo. Para isso, o grupo Casulo experimenta com criação colaborativa o campo dos têxteis e de acessórios eletrônicos inteligentes, criados a partir do uso de Lilypad arduino plataforma eletrônica projetada pela engenheira cientista no MIT Leah Beachley, para criação de computação vestível. A placa Lilypad Arduino é considerada uma ferramenta própria para a nossa vestimenta, pois ela é pequena, lavável, open source e open hardware.

\section{CONTEXTO: computação vestível afetiva e o corpo}

Em 1997, Steve Mann cunhou o termo "Computação Vestível". Esse termo, ao ser combinado com a arte, design e moda, parece solicitar novas denominações tais como: têxteis eletrônicos (e-textiles), tecidos/roupas/jóias inteligentes, sensores têxteis, moda tecnológica, entre outros que melhor abraçam as características de

nossas vestimentas. O maleável, o confortável, o flexível, e o lavável são características próprias das roupas e acessórios vestíveis.

Neste contexto, podemos encontrar dispositivos que integram componentes eletrônicos e processadores em tecidos e acessórios vestíveis. Esse tecido eletrônico torna-se capaz então de, por exemplo, através de sensores, detectar parâmetros do ambiente e do corpo do usuário tais como: estímulos mecânicos, químicos, eletrônicos e magnéticos. Além dos sensores, os tecidos eletrônicos podem agir no corpo ou no ambiente através de atuadores, modificando a cor, a forma, emitindo sons, entre outras possibilidades expressivas do tecido ou item vestível.

Pulseiras, relógios e roupas inteligentes podem hoje monitorar e oferecer diferentes informações, tais como batimentos cardíacos, contagem de passos, temperatura, e outros dados deixados como rastros da intimidade, fornecidos pelo contato com o corpo do usuário. Portanto, através do estudo sobre os tipos de interações possíveis entre o individuo e o produto, o grupo de pesquisa tem como objetivo principal identificar e ampliar formas de exibir conteúdo emocional por meio de roupas. Para isso torna-se necessário entendermos como podemos mapear e criar padrões de afetos por meio de computadores vestíveis.

E neste sentido, Picard (1998, 13-14) nos traz algumas pistas apresentando cinco principais características que todo computador vestível afetivo precisa ter: (1) o comportamento do sistema parece semelhante às emoções humanas; (2) O sistema responde a estímulos ; (3) Gera emoções com base no entendimento de situações, com base em objetivos, padrões, preferências e expectativas; (4) Possui experiência emocional (percepção cognitiva e psicológica); (5) Imitam a cognição humana e suas funções físicas (memória, decisão, planejamento,

interesse, aprendizado, motivações, prioridades, funções do sistema imunológico, combinação e variação de sentimentos, regulação e adaptação). Fatores como esses nos fazem pensar que deveríamos buscar novas formas de lidar com estas novas tecnologias que levem em consideração, em maior grau, a presença do corpo.

Outro fator importante que ressaltamos é o uso de dispositivos embutidos em roupas que se adaptem às relações pessoais, emoções, situações de trânsito, deslocamento e mobilidade do corpo humano e seus afetos.

\section{CULTURA MAKER E DIY COM COSTURA ELETRÔNICA}

A partir da discussão sobre às mudanças que o corpo, suas vestes e tecnologias anexas vem passando, buscamos realizar em nossos encontros também, práticas/fazeres manuais (costura, bordado, solda, esquemas eletrônicos, desenhos técnicos) para criação de computação vestível. Essas práticas estão baseadas em um tipo de abordagem de pesquisa/ensino/aprendizagem mais voltada para a cultura maker, DIY (do it yourself, em português: faça você mesmo).

Segundo Filard (2018) o movimento maker teve seu início nos Estados Unidos por volta da década de 70, tornandose mais conhecido a partir de 2005, com o lançamento da revista Make Magazine e do evento anual Feira Maker.

Com o intuito de investigar processos, técnicas e materiais mais próprios aos têxteis, esse empreendimento de pesquisa e produção artística, em princípio, baseou-se em experimentar como técnicas e processos de artesanato, costura e bordado, poderiam ser aplicados a procedimentos de eletrônica e ciência da computação. Para isso, apoiamos nas comunidades de software e hardware livre Arduino.

O primeiro encontro do grupo Casulo, foi realizado em 25 de setembro de 2019 no laboratório da instituição e teve como objetivo apresentar possibilidades de criação de circuitos simples em superfícies flexíveis. Cabe ressaltar que computação vestível, por ser uma área interdisciplinar, solicita um tipo de trabalho colaborativo, pois seu processo de criação pode necessitar diferentes processos: o planejamento e design da peça, costura, criação do circuito físico eletrônico, entre outros. 
Os processos realizados pelo grupo também encontram suas bases no movimento STEAM, que parte da interdisciplinaridade entre ciência, tecnologia, engenharia, artes e matemática. Com estudo sobre o comportamento da energia, sobre átomos, interação entre os corpos, cálculos matemáticos, experimentos químicos, entre outros procedimentos em laboratório, que são mais consideradas do âmbito da ciência. Como podemos ver nos seguintes experimentos:

\subsection{Atualização da interface Bússola tátil.}

O objeto de computação vestível denominado Bússola tátil (2015 - 2019) passou por várias modificações e versões. A última, realizada em 2019 (Figura 1), visou aprofundar na pesquisa sobre como a memória, por meio de dispositivos vestíveis, pode, além de gravar a intimidade do corpo, ser também sentida pelo tato. Teve como ponto de partida descobrir como uma roupa poderia "memorizar" o trajeto realizado pelo corpo e depois como apresentar esse mesmo trajeto realizado, reproduzindo esses dados em forma de "memórias físicas", para serem sentidas sobre a pele/roupa de outra pessoa/momento.

Na versão atual (Figura 1) foram costurados: pequenos vibra motores, controlados por um micro-controlador Arduino, uma mini-bússola digital capaz de capturar a posição espacial do usuário segundo os eixos norte, sul, leste e oeste e uma unidade de medida inercial. Esse sistema eletrônico conta com um mecanismo para contagem de passos a fim de informar ao usuário a quantidade de passos até o waypoint seguinte.

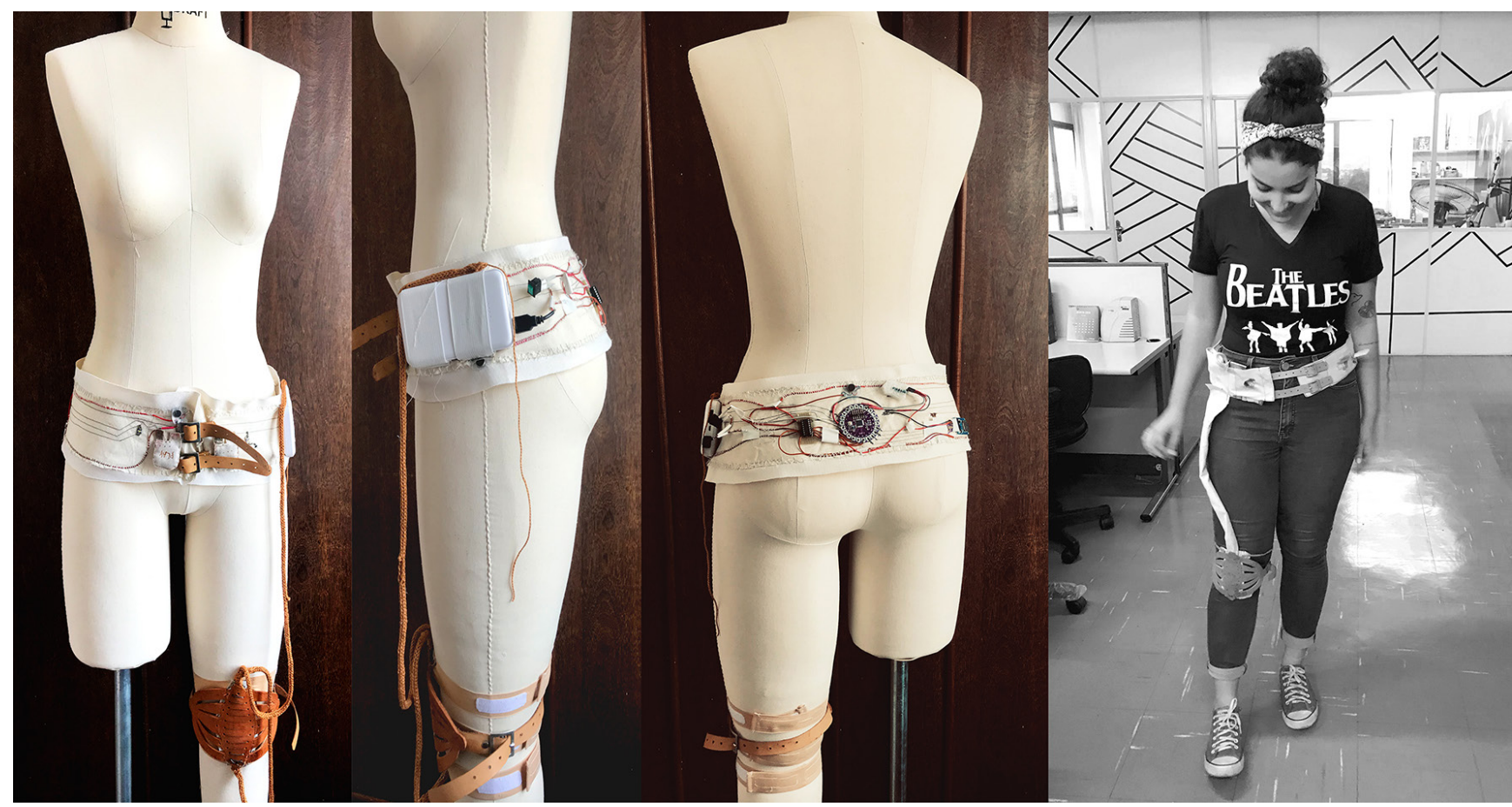

Figura 1 - Cinto Bússola Tátil. 2019. Fonte: acervo do Grupo Casulo.
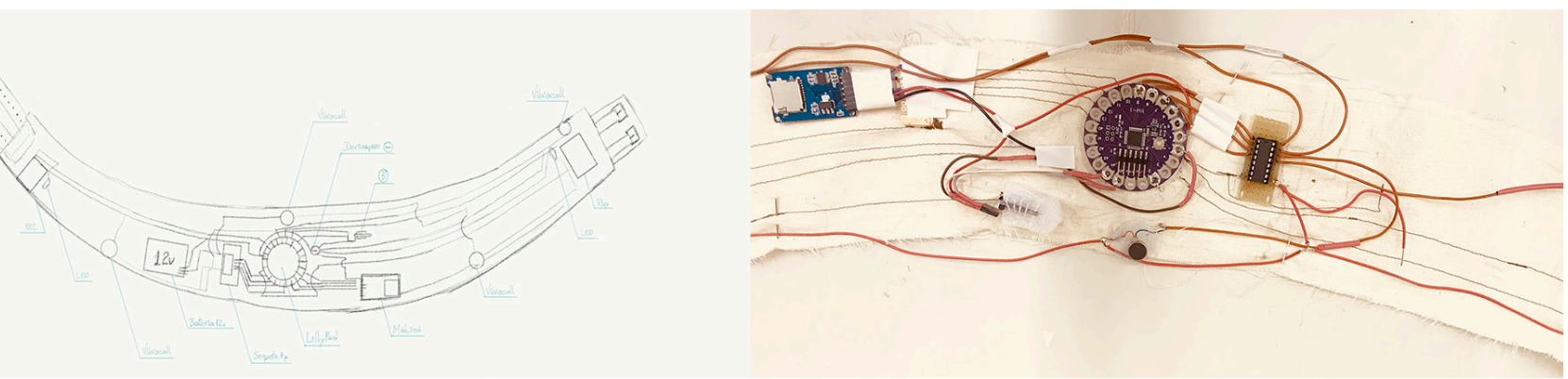

Figura 2 - Desenho esquemático e montagem dos componentes. 2019. Fonte: acervo do Grupo Casulo 


\subsection{Criação de circuito com tinta termo-crômica.}

Também foi criado um dispositivo que capta batimentos cardíacos e muda a cor de um dispositivo-tecido-pele (Figura 3), quando recebe uma mudança de dados. O microcontrolador Arduino foi programado para "ligar" e acionar a porta digital que esquenta a linha condutora, fazendo que sobre ela e em sua volta, onde haja tinta termocrômica, mude cor, do vermelho para o claro.

\section{CONSIDERAÇÕES FINAIS}

A escolha em partir deste contexto sobre o afeto e a emoção, para criação de dispositivos vestíveis, nos permitiu experimentar as hipóteses de que o corpo contemporâneo necessita de roupas que melhor se adaptem aos aspectos de mobilidade, trânsito, conexão generalizada, entre outras adaptações aos "novos modos de ser". Vimos que os processo de criação com computação vestível é interdisciplinar e necessita de conhecimentos específicos em várias áreas, e da interação dos integrantes do grupo com as comunidades de software e hardware livre. Necessita também conhecimento sobre processos artesanais, costura, bordado, entre outras técnicas que são transmitidas de modo familiar e a partir das referidas redes de cultura maker, DIY e Steam.

\section{REFERÊNCIAS}

Buechley, Leah. (2020). LilyPad Arduino. (1.8.11). http:// leahbuechley.com/?p=81.

Filardi, M. H. (2018). STEM, STEAM, Maker... O que esses novos conceitos têm de antigos? Congresso de Pesquisa do Ensino do SinproSP.

Mann, S. (1998, May 12). Definition of "Wearable Computer." http://wearcomp.org/wearcompdef.html

Picard, R. (2000). Affective computing. MIT Press.

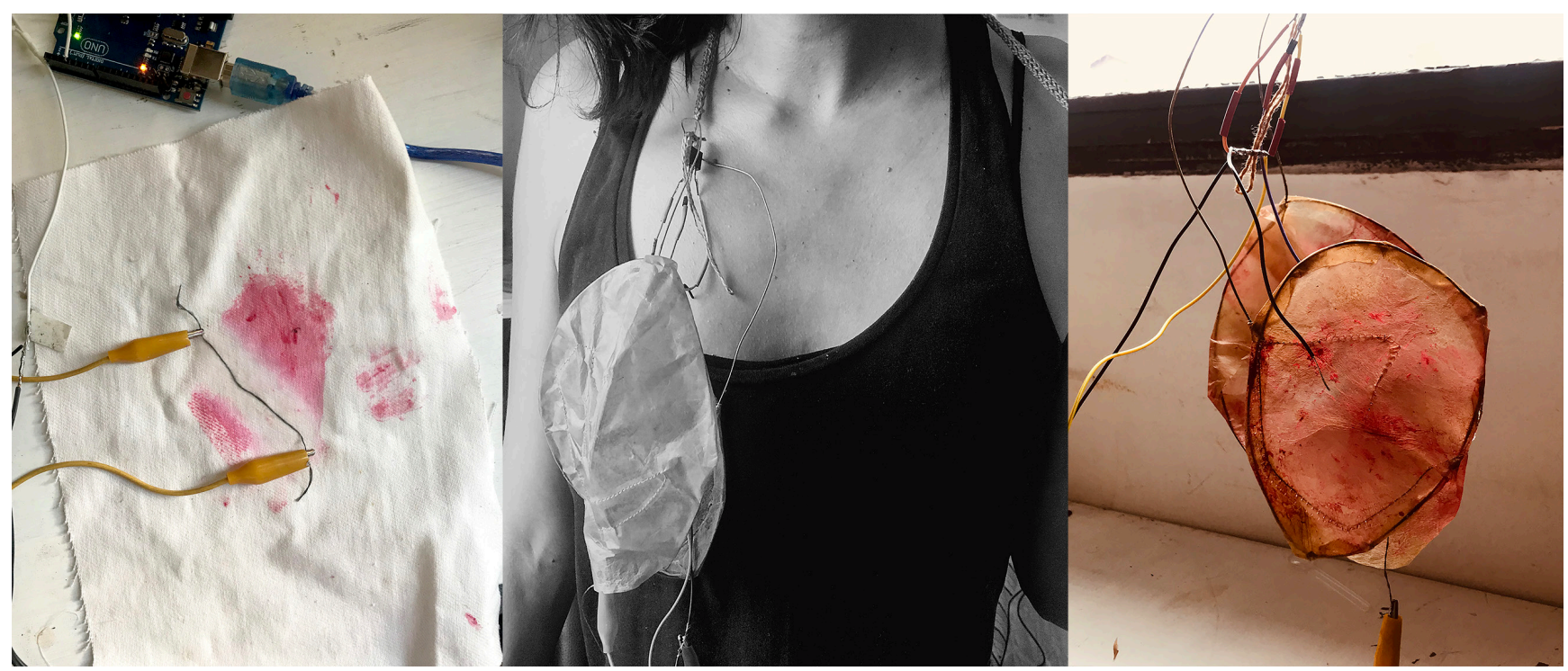

Figura 3 - Experimentos com tinta termo-crômica. 2019. Fonte: acervo do Grupo Casulo 